\title{
Fibroblast Growth Factor 23 and Left Ventricular Hypertrophy in Hemodialysis Patients
}

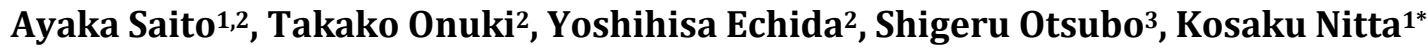 \\ ${ }^{1}$ Department of Medicine, Kidney Center, Tokyo Women's Medical University, Tokyo, Japan \\ ${ }^{2}$ Department of Medicine, Towa Hospital, Tokyo, Japan \\ ${ }^{3}$ Department of Blood Purification, Sangenjaya Hospital, Tokyo, Japan \\ Email: ${ }^{*}$ knitta@kc.twmu.ac.jp
}

Received 7 July 2014; revised 8 August 2014; accepted 10 September 2014

Copyright $@ 2014$ by authors and Scientific Research Publishing Inc.

This work is licensed under the Creative Commons Attribution International License (CC BY). http://creativecommons.org/licenses/by/4.0/

(c) (i) Open Access

\begin{abstract}
Background: Left ventricular hypertrophy (LVH) is a common cardiovascular complication and an independent risk factor for cardiovascular death in hemodialysis (HD) patients. Previous studies have shown that fibroblast growth factor 23 (FGF23), which has an important role in phosphate metabolism, is elevated in HD patients. Objectives: The aim of this study was to determine the association of FGF23 and LVH and the prognostic value of serum FGF23 level in HD patients. One hundred seven HD patients were evaluated for LVH by echocardiography. Serum FGF23 levels were measured using a commercial enzyme-linked immunosorbent assay kit. Results: Patients with LVH were more likely to have higher systolic blood pressure (BP) and LVH was significantly associated with female gender and higher serum levels of phosphate and calcium $\times$ phosphate products. LVH was also associated with higher serum FGF23 level. Multivariate analysis indicated that serum FGF23 level, systolic BP, and serum phosphate level remained correlated with LVH. This suggested that serum FGF23 level is independently associated with LVH in our HD patients. Cox analysis indicated no significant difference in risk of death for patients with elevated serum FGF23 level. Conclusion: LVH has a high prevalence in HD patients, and FGF23 is independently associated with LVH but is not a predictor for prognosis during a 4-year follow-up period.
\end{abstract}

\section{Keywords}

Fibroblast Growth Factor 23, Hemodialysis, Left Ventricular Hypertrophy, Prognosis

\footnotetext{
${ }^{*}$ Corresponding author.
}

How to cite this paper: Saito, A., Onuki, T., Echida, Y., Otsubo, S. and Nitta, K. (2014) Fibroblast Growth Factor 23 and Left Ventricular Hypertrophy in Hemodialysis Patients. International Journal of Clinical Medicine, 5, 1102-1110. 


\section{Introduction}

Cardiovascular disease is common in end-stage renal disease (ESRD) patients and the majority of deaths in hemodialysis (HD) patients are cardiovascular deaths, followed by infection and stroke in Japan [1]. Left ventricular hypertrophy $(\mathrm{LVH})$ is one of the most common cardiovascular complications in HD patients [2] [3]. Moreover, $\mathrm{LVH}$ is an independent risk factor for cardiovascular death in patients who have received maintenance HD therapy [4] [5].

The pathogenic factors involved in LVH have generally been divided into three categories [6]: 1) afterload related such as hypertension and arterial calcification; 2) preload related including expansion of intravascular volume and large flow arterio-venous fistulas; and 3) neither after load nor preload related. However, aggressive control of blood pressure (BP) and anemia does not prevent LVH in HD patients [7]. Thus, it seems likely that other factors play a role in the initiation and progression of LVH in HD patients.

Hyperphosphatemia is common in HD patients [8] and control of serum phosphate level correlates with a reduction in left ventricle mass index (LVMI) in these patients [7]. It has been suggested that a novel mechanism may be responsible for the association of elevated serum phosphate and LVH and the subsequent deleterious effects on cardiovascular outcomes among HD patients. However, the exact mechanism is still unknown.

The phosphatonins, such as fibroblast growth factor 23 (FGF23), may act on multiple organs in autocrine, paracrine, and endocrine modes to regulate phosphate metabolism [9]. FGF23 decreases blood phosphate concentrations by directly reducing renal phosphate reabsorption and by suppressing $1 \alpha-25(\mathrm{OH})_{2} \mathrm{D}$ formation through the inhibition of $1 \alpha$-hydroxylase [10]. Moreover, FGF23 is one of the major phosphatonins and is elevated in chronic HD patients [11].

The previous studies suggest that elevation of serum FGF23 levels may be related to the development of LVH and clinical outcome for HD patients. The aim of the present study was to evaluate the association between serum FGF23 level and LVH and clinical outcome in HD patients.

\section{Methods}

\subsection{Study Design and Population}

This is an observational and prospective cohort study. The subjects of this study were treated in the dialysis center of Towa Hospital (Tokyo, Japan). Each patient underwent HD three times weekly (4 hours/day). Blood pressures (BP) were measured with a mercury sphygmomanometer with the patient in the supine position after 10 to 15 minutes of rest, and mean values for 1 month at enrollment were used for the analysis. This study was in compliance with the Declaration of Helsinki and was approved by the Institutional Review Board of Towa Hospital. All subjects gave their informed consent.

This dialysis center has 120 chronic HD patients who are on regular dialysis for more than 6 months. A total of 107 outpatients were randomly selected for participation by creation of a randomized list. All subjects were 20 to 80 years old, were on chronic HD for more than 6 months, and received standardized HD prescriptions (500 mL/min dialysate flow; 200 - $250 \mathrm{~mL} / \mathrm{min}$ blood flow; 4 hours dialysis per session; 3 sessions per week). All patients were dialyzed using bicarbonate-containing baths.

\subsection{Echocardiographic Examination}

The echocardiograms were performed on echocardiography equipment, an Vivid S6 (GE Healthcare, Tokyo, Japan) ultrasound imager equipped with a 2.2/4.4 MHz (harmonics) phased-array 3S transducer during continuous electrocardiographic recording as previously described [12]. Left ventricular mass (LVM) was calculated according to a formula derived by Devereux and Reichek [13] and indexed for body surface area (BSA) to give LVMI. Patients were considered to have LVH if the LVMI was greater than $134 \mathrm{~g} / \mathrm{m}^{2}$ for men and greater than $110 \mathrm{~g} / \mathrm{m}^{2}$ for women [14].

$$
\operatorname{LVM}(g)=1.04 \times\left([\operatorname{LVEDd}+\operatorname{IVST}+\mathrm{LVPWT}]^{3}-[\mathrm{LVESD}]^{3}\right)-13.6
$$

LVMI $\left(\mathrm{g} / \mathrm{m}^{2}\right)$ = left ventricle mass (LVM)/BSA. Where LVPWT is left ventricular posterior wall thickness; IVST is interventricular septum thickness; LVEDD is left ventricular end-diastolic diameter; and LVESD is left ventricular end-systolic diameter. 


\subsection{Clinical and Laboratory Data}

Clinical data, including age, gender, comorbidities and dialysis vintage were obtained from detailed analysis of medical records and interviews with the patient and the attending physician, when necessary. Before performing each echocardiogram, BP was measured and anthropometric data and ratios were obtained (weight, height, BSA), which were measured according to standard procedures and using suitable materials. The body mass index (BMI) was calculated by dividing weight $(\mathrm{kg})$ by squared height $(\mathrm{m})$. The BSA was obtained using the formula of Dubois and Dubois [15]. All biochemical measurements were performed by a single laboratory, located in Towa Hospital, and data were collected from patients' charts.

We obtained complete laboratory data and dialysis-related data for all patients. Laboratory data included hemoglobin concentration, serum levels of albumin, calcium, phosphate, intact parathyroid hormone (PTH), total cholesterol, HDL-cholesterol, triglyceride, and C-reactive protein (CRP). In addition, urea clearance (Kt/V, calculated by the Daugirdas method), was calculated for assessment of adequacy of dialysis. Hemoglobin, albumin, calcium, phosphate, total cholesterol, HDL-cholesterol, triglyceride, CRP, blood urea nitrogen, and creatinine concentrations were determined with standard autoanalyzer. Serum calcium levels were adjusted using the formula [calcium +(4-albumin)]. Serum intact PTH levels were measured using a commercially available radioimmunoassay kit (Nichol's Institute, San Juan Capistrano, CA, USA). Serum intact FGF23 level was measured using an enzyme-linked immunosorbent assay kit (Kainos Laboratories Inc., Tokyo, Japan) as previously described [16]. The intra-assay and inter-assay variations of FGF23 measurements were 3\% and 4\% to 6\%, respectively. Serum samples for measurement of other laboratory data were collected at the same time.

Patients were considered diabetic if they met the 1997 American Diabetes Association criteria; hypertensive if predialytic systolic BP was greater than $140 \mathrm{~mm} \mathrm{Hg}$, diastolic BP was greater than $90 \mathrm{~mm} \mathrm{Hg}$, or if they were using any antihypertensive therapy. The presence of coronary heart disease was confirmed by coronary angiography. Stroke was determined by clinical symptoms and computer tomography. Pulse pressure is the difference between systolic and diastolic BPs.

\subsection{Outcomes}

The primary endpoint or cardiovascular mortality was defined by death from cardiovascular causes (including sudden death, myocardial infarction and cerebrovascular accidents). The secondary outcomes included overall mortality. Outcomes were obtained from monthly review of medical documentation, including medical records and death certificates, as well as communication with the physician and patient's relatives. Patients who underwent kidney transplant or who switched dialysis modality were censored in the study.

\subsection{Statistical Analysis}

Continuous variables are expressed as means \pm SD and categorical variables as percentages. Two-tailed Student unpaired $t$ test was employed to evaluate the difference between means and a $\chi^{2}$ test was used to assess the association between or among the categorical parameters. The significant factors $(P<0.1)$ were then subject to multivariate analysis with stepwise (forward) regression analysis to test for interaction between the different significant covariates. Survival analyses were expressed using the Kaplan-Meier survival curve or the Cox proportional hazard model. Overall patient survival was analyzed by a Cox proportional hazards model to control for covariates. Cox proportional hazards regression models were applied to compare survival in the patients with low- and high-FGF23 level. The models were adjusted for the effect of independent mortality risk factors including age, dialysis vintage, systolic BP, serum phosphate level. The probability of survival free from cardiovascular cause was also analyzed by the Kaplan-Meier survival curve. All statistical analyses were performed with JMP 10.0.1 (SAS Institute, Cary, NC, USA) and a $P$ value $<0.05$ was considered statistically significant.

\section{Results}

Table 1 shows the demographic characteristics and clinical data of all study patients. Mean patient age was $65.5 \pm$ 10.5 years and 69 men (65.0\%). The mean dialysis vintage was $14.1 \pm 11.5$ years. Causes of ESRD were diabetes mellitus in 41 (38.0\%) patients and non-diabetes in 66 (62.0\%) patients. Approximately, 64\% of patients had hypertension. Fifty-three patients (49.5\%) had LVH. The serum FGF23 levels of the patients were high, with a mean 18,916 pg/mL (range 71.2 - 282987.9 pg/mL). 
Table 1. Baseline characteristics and laboratory data of hemodialysis patients with and without LVH.

\begin{tabular}{|c|c|c|c|c|}
\hline & Total & No LVH & LVH & \\
\hline Characteristics & $\mathrm{N}=107(\%)$ & $\mathrm{N}=54(\%)$ & $\mathrm{N}=53(\%)$ & $P$ \\
\hline Age (years) & $65.5 \pm 10.5$ & $64.5 \pm 11.2$ & $66.5 \pm 9.6$ & 0.327 \\
\hline Male (\%) & $69(65)$ & $40(74)$ & $29(55)$ & 0.029 \\
\hline Dialysis vintage (years) & $14.1 \pm 11.5$ & $13.9 \pm 8.2$ & $14.4 \pm 14.3$ & 0.827 \\
\hline Diabetes & $41(38)$ & $16(30)$ & $25(47)$ & 0.075 \\
\hline Hypertension & $64(60)$ & $24(44)$ & $40(76)$ & $0.001 \%$ \\
\hline Previous cardiovascular disease & $18(17)$ & $6(11)$ & $12(23)$ & 0.090 \\
\hline Hypercholesterolemia $^{\mathrm{a}}$ & $9(8)$ & $5(9)$ & $4(7)$ & 0.488 \\
\hline Systolic BP (mm Hg) & $143.2 \pm 22.1$ & $138.4 \pm 23.0$ & $148.1 \pm 20.3$ & $0.023 \%$ \\
\hline Diastolic BP (mm Hg) & $81.8 \pm 12.3$ & $79.8 \pm 11.9$ & $83.8 \pm 12.5$ & 0.091 \\
\hline FGF-23 (pg/mL) & $18916 \pm 38343$ & $11142 \pm 18618$ & $26836 \pm 50169$ & $0.034 \%$ \\
\hline Hemoglobin (g/dL) & $11.2 \pm 9.1$ & $10.6 \pm 1.1$ & $11.8 \pm 13.0$ & 0.495 \\
\hline Albumin (g/dL) & $3.8 \pm 0.3$ & $3.8 \pm 0.3$ & $3.8 \pm 0.3$ & 0.660 \\
\hline cCalcium (mg/dL) ${ }^{\mathrm{b}}$ & $8.9 \pm 0.9$ & $8.7 \pm 0.8$ & $9.0 \pm 1.0$ & 0.210 \\
\hline Phosphate (mg/dL) & $6.0 \pm 1.1$ & $5.7 \pm 1.0$ & $6.2 \pm 1.1$ & $0.035 \%$ \\
\hline $\mathrm{Ca} \times \mathrm{P}^{\mathrm{c}}$ & $53.2 \pm 12.0$ & $50.7 \pm 11.3$ & $55.8 \pm 12.2$ & $0.029 *$ \\
\hline Intact PTH & $223.9 \pm 113.2$ & $223.6 \pm 113.0$ & $224.1 \pm 114.6$ & 0.983 \\
\hline CRP & $0.35 \pm 0.71$ & $0.34 \pm 0.74$ & $0.36 \pm 0.69$ & 0.875 \\
\hline $\mathrm{Kt} / \mathrm{V}$ & $1.21 \pm 0.10$ & $1.22 \pm 0.10$ & $1.19 \pm 0.11$ & 0.132 \\
\hline
\end{tabular}

Values expressed as mean \pm SD or percent. ${ }^{a}$ Hypercholesterolemia was defined as total cholesterol more than $200 \mathrm{mg} / \mathrm{dL}$. ${ }^{\mathrm{b}} \mathrm{Calcium}$ is corrected as calcium $+(4.0$-albumin $) .{ }^{\mathrm{c}} \mathrm{Ca} \times \mathrm{P}$ is the product of calcium and phosphate. ${ }^{*} \mathrm{P}<0.05,{ }^{*} \mathrm{P}<0.01$. BP, blood pressure; LVH, left ventricular hypertrophy; FGF, fibroblast growth factor; PTH, parathyroid hormone; CRP, C-reactive protein.

All patients who received echocardiography were examined for LVH. Patients with LVH were more likely to have higher systolic BP and LVH was significantly associated with female gender and higher serum levels of phosphate and calcium $\times$ phosphate products (Table 1). LVH was also associated with higher levels of FGF23 $(26,836 \pm 50,169 \mathrm{pg} / \mathrm{mL}$ versus $11,142 \pm 18,618 \mathrm{pg} / \mathrm{mL}, P=0.030)$ (Figure 1$)$. The presence of LVH was not associated with age, dialysis vintage, diabetes mellitus, previous cardiovascular disease, Kt/V, hypercholesterolemia, hemoglobin, serum levels of albumin, CRP, corrected calcium, or intact PTH.

To test for possible interactions between different significant covariates in our initial analysis (Table 2), we entered significant association factors $(P<0.1)$ from this analysis into a multivariate analysis with stepwise regression. In this multivariate analysis, female gender, serum FGF23 level, serum phosphate level, and systolic BP remained associated with LVH. This suggested that serum FGF23 level is independently associated with LVH in our HD patients.

Next, we examined the possible prognostic value of serum FGF23 level by following all study patients for 4 years. During this follow-up period, 18 deaths occurred, 6 were because of congestive heart failure, 4 were because of acute myocardial infarction, 4 were because of septic shock, 2 were because of cerebellar infarction, 1 was cerebellar bleeding and 1 was because of pneumonitis.

In view of the wide distribution of serum FGF23 levels in our patients, we divided patients into a high FGF23 group and a low FGF23 group, using the median FGF23 value of $4140 \mathrm{pg} / \mathrm{mL}$ as the dividing point. A Cox analysis indicated that the risk of death did not differ significantly between high- and low-FGF23 groups (Figure 2). The analysis adjusted for age, dialysis vintage, systolic BP, and serum phosphate level (high FGF23 versus low FGF23, hazard ratio: 0.725, 95\% CI: 0.237 - 2.170, $P=0.564$ ). In addition, Kaplan-Meier survival curve analysis of cardiovascular disease-related death in high- and low-FGF23 patients found no significant difference between these groups (log rank test, $P=0.367$ ) (Figure 3). 


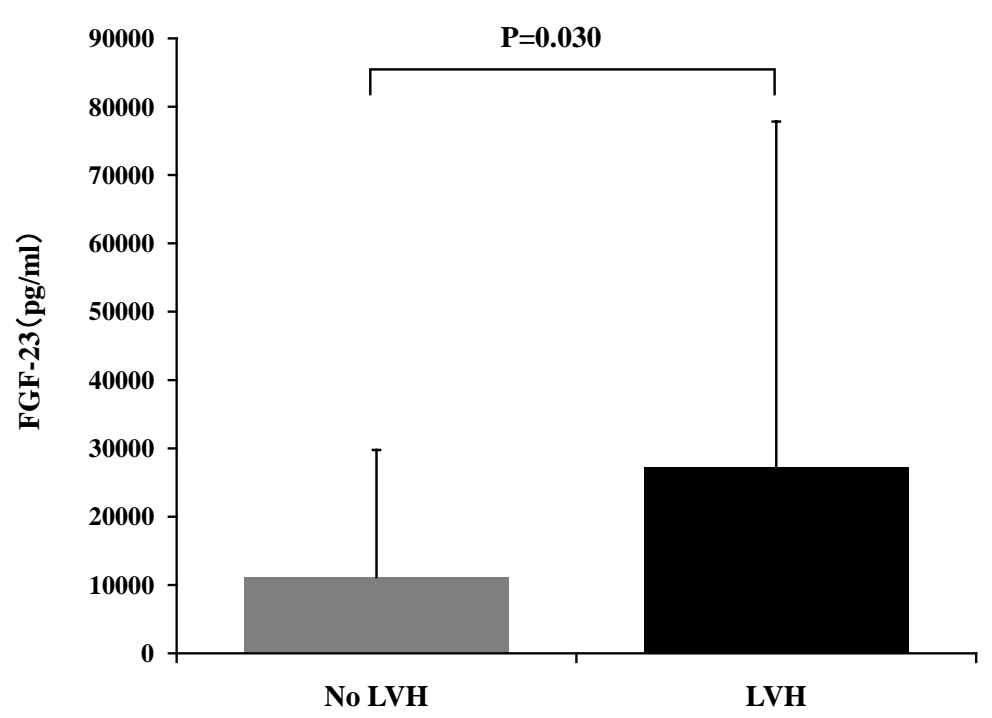

Figure 1. Serum fibroblast growth factor 23 (FGF23) level in hemodialysis patients with left ventricular hypertrophy $(\mathrm{LVH})$ and without $\mathrm{LVH}$.

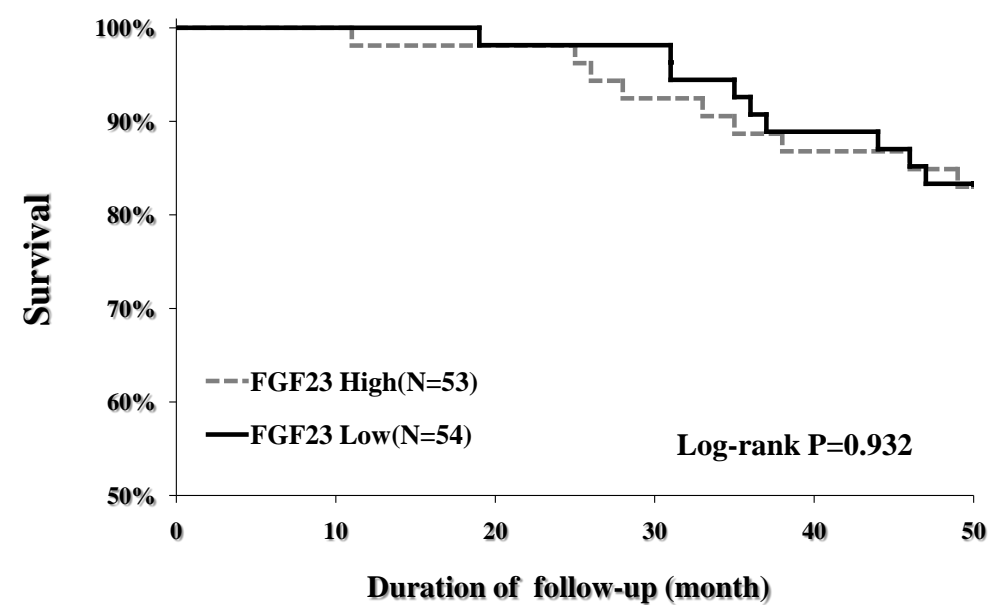

Figure 2. Probability of survival in patients with low FGF23 and high FGF23.

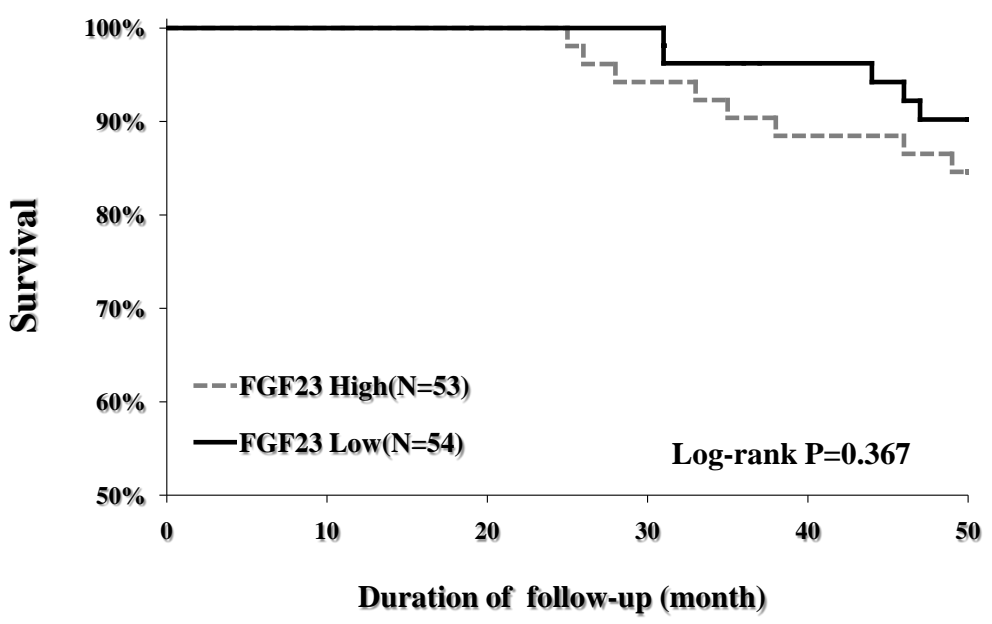

Figure 3. Probability of survival free from cardiovascular disease for patients with low FGF23 and high FGF23. 
Table 2. Independent predictors for LVH in hemodialysis patients.

\begin{tabular}{ccccccc}
\hline & Univariate odds ratio & 95\% confidence interval & $P$ & Multivariate odds ratio $^{*}$ & 95\% confidence interval & $P^{a}$ \\
\hline Male & 0.423 & $0.184-0.944$ & $0.036^{*}$ & 0.331 & $0.132-0.787$ & $0.012^{*}$ \\
Phosphate & 1.480 & $1.031-2.179$ & $0.034^{*}$ & 1.648 & $1.117-2.507$ & $0.011^{*}$ \\
FGF-23 & 1.016 & $1.002-1.034$ & $0.020^{*}$ & 1.021 & $1.004-1.302$ & $0.038^{*}$ \\
Systolic BP & 1.021 & $1.003-1.041$ & 0.022 & 1.025 & $1.006-1.046$ & $0.009^{*}$ \\
\hline
\end{tabular}

${ }^{a} P$ from logistic regression adjusted for gender, phosphate, FGF-23, and systolic blood pressure. $P<0.05$. FGF; fibroblast growth factor.

\section{Discussion}

The results of the present study show that serum FGF23 level was independently associated with the presence of LVH and were compatible with those of the previous studies [17]-[21]. Elevated serum FGF23 levels have been reported to be linked to greater risks of mortality in patients with chronic kidney disease [22] [23]. However, we found that elevated serum FGF23 level during the follow-up period of 4 years did not predict outcome. The causality of the association between elevated circulating levels of FGF23 and adverse outcomes remains to be established.

LVH develops early during the course of renal impairment and is presumably a consequence of volume and pressure overload [24]. Even when there is control of volume by frequent adjustment of dry weight and aggressive use of antihypertensive agent, LVH still has a high prevalence in HD patients (60\% - 90\%) [25] [26]. Thus, it is likely that other factors play a role in the initiation and progression of LVH in ESRD patients. A previous study showed that aggressive therapy for BP control and anemia by use of conventional HD therapy was associated with high level of LVH, whereas administration of short daily dialysis sessions and correction of elevated serum phosphate level were associated with low levels of LVH [7].

Poor control of serum phosphate and the calcium-phosphorous product is known to be associated with increased LVM [27]. Previous in vitro studies also showed that high levels of phosphate can induce intracellular changes and changes in cellular phenotype [28], suggesting that hyperphosphatemia may promote LVH by altering vascular reactivity or by inducing endothelial or vascular smooth muscle phenotypic changes and thereby changes the systemic vascular resistance and endothelial function. These studies show that poor control of mineral metabolism plays a role in the pathogenesis of LVH in HD patients.

The renin-angiotensin system (RAS) plays a central role in increased cardiovascular morbidity and mortality through various effects such as worsened hypertension, baroreceptor dysfunction, sympathetic activation, progression of atherosclerosis, endothelial dysfunction, and LVH [29]. Activation of the RAS by FGF23 could explain the association with LVH, since activated RAS is a known risk factor for pathologic myocardial hypertrophy [30]. It is unclear whether elevated serum FGF23 levels are associated with the RAS activation as a pivotal role of FGF23-induced LVH.

Another possible mechanism directly linking FGF23 to adverse cardiovascular events is its putative effect on inflammation. Inflammation is common in ESRD and it is associated with significantly worse outcomes. Experimental data suggest that FGF23 increases production of inflammatory markers such as lipocalin-2, transforming growth factor- $\beta$ and tumor necrosis factor- $\alpha$ [31]. Elevated serum FGF23 levels have been found to be associated with inflammatory markers in an observational study [32].

The limited tissue distribution of Klotho, which is necessary for FGF23 action through FGF receptor, limits the actions of FGF23 to various organs. However, the effects of FGF23 on heart tissue that do not express Klotho could occur by virtue of its suppressing effects on Klotho production, and consequently its lowering of circulating levels of Klotho, which has various metabolic effects [33]. Since myocardial cells do not express Klotho, the experimental study challenges the prevailing paradigm that the effects of FGF23 on the FGF receptor are weak without the concomitant presence of Klotho, even at high concentrations of FGF23 [34].

$\mathrm{LVH}$ is an adaptive response to an increase in cardiac workload that has short-term beneficial effects on cardiac function, but is detrimental in the long term [6]. LVH is a well-known risk factor for mortality of HD patients. Our study showed that elevation of serum FGF23 level is an independent factor for LVH. However, we found no prognostic value for elevated serum FGF23 level during the 4-year follow-up period after adjusting for age, dialysis vintage, systolic BP, and serum phosphate level. Thus, it is likely that the impact of FGF23 on 
mortality of HD patients may be blunted in the grade of hyperphosphatemia [16].

One possible explanation is that prognosis of HD patients depends upon a complex interaction of numerous factors. Elevation of FGF23 is associated with the presence of LVH, elevated phosphate, and elevation of product of calcium and phosphate. Vascular calcification, induced by an excess of calcium and phosphate, is a major risk factor that is independently associated with cardiovascular events and death [35]. Scialla et al. have recently shown that FGF23 is not associated with and does not induce arterial calcification [36]. Thus, it is likely that the confounding factor of phosphate and the products of calcium and phosphate may cause FGF23 to have poor prognostic value.

There were several limitations in this study. First, the sample size and the events were small, and despite careful adjustments in our statistical analyses, it was impossible to rule out the residual confounding factors. Second, we measured serum FGF23 level only at one time. The uncertain variation of FGF23 level days to days should be considered. Third, we chose patients who are $100 \%$ Japanese. Other races of patients in our study were not included. Fourth, the study follow-up period is limited to detect difference in overall survival and cardiovascular-related death.

In summary, the results of the present study showed a high prevalence of LVH and that elevation of serum FGF23 level is independently associated with LVH, but that FGF23 is not a prognostic factor for the 4-year follow-up period.

\section{Acknowledgements}

We thank medical staffs for dialysis center in the Towa Hospital for collecting medical records. This work was supported by grants from the Japan Research Promotion Society for Cardiovascular Diseases.

\section{Conflict of Interest}

The authors have declared that no conflict of interest exists.

\section{References}

[1] Nakai, S., Watanabe, Y., Masakane, I., Wada, A., Shoji, T. Hasegawa, T., et al. (2013) Overview of Regular Dialysis Treatment in Japan (as of 31 December 2011). Therapeutic Apheresis and Dialysis, 17, 567-611. http://dx.doi.org/10.1111/1744-9987.12147

[2] Foley, R.N., Parfrey, P.S., Harnett, J.D., Kent, G.M., Murray, D.C. and Barre, P.E. (1995) Clinical and Echocardiographic Disease in Patients starting End-Stage Renal Disease Therapy. Kidney International, 47, 186-192. http://dx.doi.org/10.1038/ki.1995.22

[3] Middleton, R.J., Parfrey, P.S. and Foley, R.N. (2001) Left Ventricular Hypertrophy in the Renal Patient. Journal of American Society of Nephrology, 12, 1079-1084.

[4] Silberberg, J.S., Barre, P.E., Prichard, S.S. and Sniderman, A.D. (1989) Impact of Left Ventricular Hypertrophy on Survival in End-Stage Renal Disease. Kidney International, 36, 286-290. http://dx.doi.org/10.1038/ki.1989.192

[5] London, G.M., Pannier, B., Guerin, A.P., Blacher, J., Marchais, S.J., Darne, B., et al (2001) Alterations of Left Ventricular Hypertrophy in and Survival of Patients receiving Hemodialysis: Follow-Up of an Interventional Study. Journal of American Society of Nephrology, 12, 2759-2767.

[6] Glassock, R.J., Pecoits-Filho, R. and Barberato, S.H. (2009) Left Ventricular Mass in Chronic Kidney Disease and ESRD. Clinical Journal of American Society of nephrology, Suppl 1, S79-S91. http://dx.doi.org/10.2215/CJN.04860709

[7] Ayus, J.C., Mizani, M.R., Achinger, S.G., Thadhani, R., Go, A.S. and Lee, S. (2005) Effects of Short Daily versus Conventional Hemodialysis on Left Ventricular Hypertrophy and Inflammatory Markers: A Prospective, Controlled Study. Journal of American Society of Nephrology, 16, 2778-2788. http://dx.doi.org/10.1681/ASN.2005040392

[8] Block, G.A., Klassen, P.S., Lazarus, J.M., Ofsthun, N., Lowrie, E.G. and Chertow, G.M. (2004) Mineral Metabolism, Mortality, and Morbidity in Maintenance Hemodialysis. Journal of American Society of Nephrology, 15, 2208-2218. http://dx.doi.org/10.1097/01.ASN.0000133041.27682.A2

[9] Berndt, T. and Kumar, R. (2007) Phosphatonins and the Regulation of Phosphate Homeostasis. Annual Review of Physiology, 69, 341-359. http://dx.doi.org/10.1146/annurev.physiol.69.040705.141729

[10] Schiavi, S.C. and Kumar, R. (2004) The Phosphatonin Pathway: New Insights in Phosphate Homeostasis. Kidney International, 65, 1-14. http://dx.doi.org/10.1111/j.1523-1755.2004.00355.x 
[11] Imanishi, Y., Inaba, M., Nakatsuka, K., Nagasue, K., Okuno, S., Yoshihara, A., et al. (2004) FGF-23 in Patients with End-Stage Renal Disease on Hemodialysis. Kidney International, 65, 1943-1946. http://dx.doi.org/10.1111/j.1523-1755.2004.00604.x

[12] Koeda, M., Ogawa, T., Ito, K., Tsutsui, T. and Nitta, K. (2014) Echocardiographic Parameters as Cardiovascular Mortality Predictors in Chronic Hemodialysis Patients. International Journal of Clinical Medicine, 5, 635-643.

[13] Devereux, R.B. and Reichek, N. (1977) Echocardiographic Determination of Left Ventricular Mass in Man. Anatomic Validation of the Method. Circulation, 55, 613-618. http://dx.doi.org/10.1161/01.CIR.55.4.613

[14] Devereux, R.B., Koren, M.J., de Simone, G., Okin, P.M. and Kligfield, P. (1993) Methods for Detection of Left Ventricular Hypertrophy: Application to Hypertensive Heart Disease. European Heart Journal, 14, 8-15.

[15] Dubois, D. and Dubois, E.F. (1916) Clinical Calorimetry Tenth Paper. A Formula to Estimate the Approximate Surface Area if Height and Weight be Known. JAMA Internal Medicine, 17, 863-871. http://dx.doi.org/10.1001/archinte.1916.00080130010002

[16] Sugimoto, H., Ogawa, T., Iwabuchi, Y., Otsuka, K. and Nitta, K. (2014) Relationship between Serum Fibroblast Growth Factor-23 Level and Mortality in Chronic Hemodialysis Patients. International Urology and Nephrology, 46, 99-106. http://dx.doi.org/10.1007/s11255-013-0386-2

[17] Gutierrez, O.M., Januzzi, J.L., Isakova, T., Laliberte, K., Smith, K., Collerone, G., et al. (2009) Fibroblast Growth Factor 23 and Left Ventricular Hypertrophy in Chronic Kidney Disease. Circulation, 119, 2545-2552. http://dx.doi.org/10.1161/CIRCULATIONAHA.108.844506

[18] Hsu, H.J. and Wu, M.S. (2009) Fibroblast Growth Factor 23: A Possible Cause of Left Ventricular Hypertrophy in Hemodialysis Patients. American Journal of Medical Sciences, 337, 116-122. http://dx.doi.org/10.1097/MAJ.0b013e3181815498

[19] Kirkpantur, A., Balci, M., Gurbuz, O.A., Afsar, B., Canbakan, B., Akdemir, R., et al. (2011) Serum Fibroblast Growth Factor-23 (FGF-23) Levels Are Independently Associated with Left Ventricular Mass and Myocardial Performance Index in Maintenance Haemodialysis Patients. Nephrology Dialysis Transplantation 26, 1346-1354. http://dx.doi.org/10.1093/ndt/gfq539

[20] Canziani, M.E., Tomiyama, C., Higa, A., Draibe, S.A. and Carvalho, A.B. (2011) Fibroblast Growth Factor 23 in Chronic Kidney Disease: Bridging the Gap between Bone Mineral Metabolism and Left Ventricular Hypertrophy. Blood Purification, 31, 26-32. http://dx.doi.org/10.1159/000321368

[21] Knap, B., Veceric-Haler, Z., Benedik, M., Buturovic-Ponikvar, J., Ponikvar, R. and Bren, A.F. (2013) Fibroblast Growth Factor 23 and Left Ventricular Mass Index in Maintenance Hemodialysis Patients: Standard versus Long Nocturnal Hemodialysis. Therapeutic Apheresis and Dialysis, 17, 407-411. http://dx.doi.org/10.1111/1744-9987.12087

[22] Isakova, T. (2013) Fibroblast Growth Factor 23 and Adverse Clinical Outcomes in Chronic Kidney Disease. Current Opinion in Nephrology and Hypertension, 21, 334-340. http://dx.doi.org/10.1097/MNH.0b013e328351a391

[23] Zoccali, C., Yilmaz, M.I. and Mallamaci, F. (2013) FGF23: A Mature Renal and Cardiovascular Risk Factor? Blood Purification, 36, 52-57. http://dx.doi.org/10.1159/000351001

[24] Levin, A., Thompson, C.R., Ethier, J., Carlisle, E.J., Tobe, S., Mendelssohn, D., et al. (1999) Left Ventricular Mass Index Increase in Early Renal Disease: Impact of Decline in Hemoglobin. American Journal of Kidney Diseases, 34, 125-134. http://dx.doi.org/10.1016/S0272-6386(99)70118-6

[25] Chang, S.T., Chen, C.C., Chen, C.L., Cheng, H.W., Chung, C.M. and Yang, T.Y. (2004) Changes of the Cardiac Architectures and Functions for Chronic Hemodialysis Patients with Dry Weight Determined by Echocardiography. Blood Purification, 22, 351-359. http://dx.doi.org/10.1159/000080031

[26] Kutlay, S., Dincer, I., Sengul, S., Nergizoglu, G., Duman, N. and Erturk, S. (2006) The Long-Term Behavior and Predictors of Left Ventricular Hypertrophy in Hemodialysis Patients. American Journal of Kidney Diseases, 47, 485-492. http://dx.doi.org/10.1053/j.ajkd.2005.12.029

[27] Strozecki, P., Adamowicz, A., Nartowicz, E., Odrowaz-Sypniewska, G., Wlodarczyk, Z. and Manitius, J. (2001) Parathormon, Calcium, Phosphorus, and Left Ventricular Structure and Function in Normotensive Hemodialysis Patients. Renal Failure, 23, 115-126. http://dx.doi.org/10.1081/JDI-100001291

[28] Jono, S., McKee, M.D., Murry, C.E., Shioi, A., Nishizawa, Y., Mori, K., Morii, H. and Giachelli, C.M. (2000) Phosphate Regulation of Vascular Smooth Muscle Cell Calcification. Circulation Research, 87, e10-e17. http://dx.doi.org/10.1161/01.RES.87.7.e10

[29] Arnlov, J., Carlsson, A.C., Sundstrom, J., Ingelsson, E., Larsson, A., Lind, L. and Larsson, T.E. (2013) High Fibroblast Growth Factor-23 Increased the Risk of All-Cause and Cardiovascular Mortality in the Community. Kidney International, 83, 160-166. http://dx.doi.org/10.1038/ki.2012.327

[30] Faul, C., Amaral, A.P., Oskouei, B., Hu, M.C., Sloan, A., Isakova, T., et al. (2011) FGF23 Induces Left Ventricular Hypertrophy. Journal of Clinical Investigation, 121, 4393-4408. http://dx.doi.org/10.1172/JCI46122 
[31] Dai, B., David, V., Martin, A., Huang, J., Li, H., Jiao, Y., et al. (2012) A Comparative Transcriptome Analysis Identifying FGF23 Regulated Genes in the Kidney of a Mouse CKD Model. PLoS ONE, 7, e44161. http://dx.doi.org/10.1371/journal.pone.0044161

[32] Munoz Mendoza, J., Isakova, T., Ricardo, A.C., Xie, H., Navaneethan, S.D., Anderson, A.H., et al. (2012) Fibroblast Growth Factor 23 and Inflammation in CKD. Clinical Journal of the American Society of Nephrology, 7, 1155-1162. http://dx.doi.org/10.2215/CJN.13281211

[33] Quarles, L.D. (2012) Role of FGF23 in Vitamin D and Phosphate Metabolism: Implications in Chronic Kidney Disease. Experimental Cell Research, 318, 1040-1048. http://dx.doi.org/10.1016/j.yexcr.2012.02.027

[34] Zhang, X., Ibrahimi, O.A., Olsen, S.K., Umemori, H., Mohammadi, M. and Ornitz, D.M. (2006) Receptor Specificity of the Fibroblast Growth Factor Family. The Complete Mammalian FGF Family. Journal of Biological Chemistry, 281, 15694-15700. http://dx.doi.org/10.1074/jbc.M601252200

[35] Nitta, K. (2011) Vascular Calcification in Patients with Chronic Kidney Disease. Therapeutic Apheresis and Dialysis, 15, 513-521. http://dx.doi.org/10.1111/j.1744-9987.2011.00979.x

[36] Scialla, J.J., Lau, W.L., Reilly, M.P., Isakova, T., Yang, H.Y., Crouthamel, M.H., et al. (2013) Fibroblast Growth Factor 23 Is not Associated with and Does not Induce Arterial Calcification. Kidney International, 83, 1159-1168. http://dx.doi.org/10.1038/ki.2013.3 
Scientific Research Publishing (SCIRP) is one of the largest Open Access journal publishers. It is currently publishing more than 200 open access, online, peer-reviewed journals covering a wide range of academic disciplines. SCIRP serves the worldwide academic communities and contributes to the progress and application of science with its publication.

Other selected journals from SCIRP are listed as below. Submit your manuscript to us via either submit@scirp.org or Online Submission Portal.
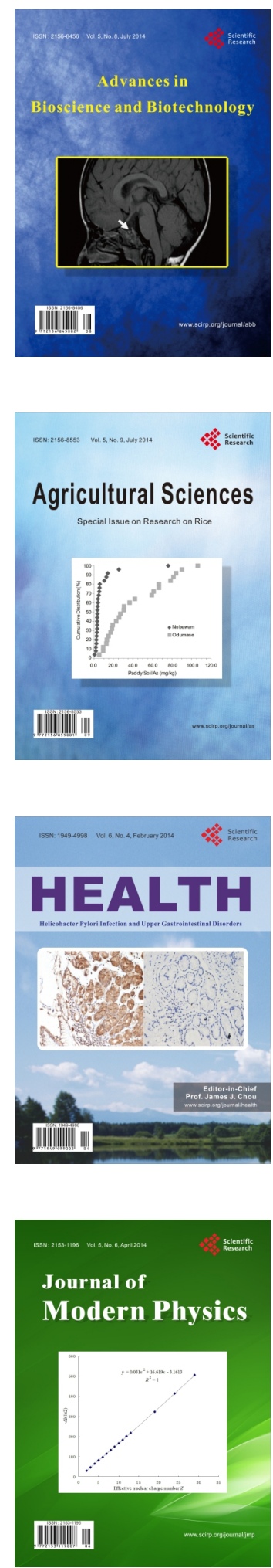
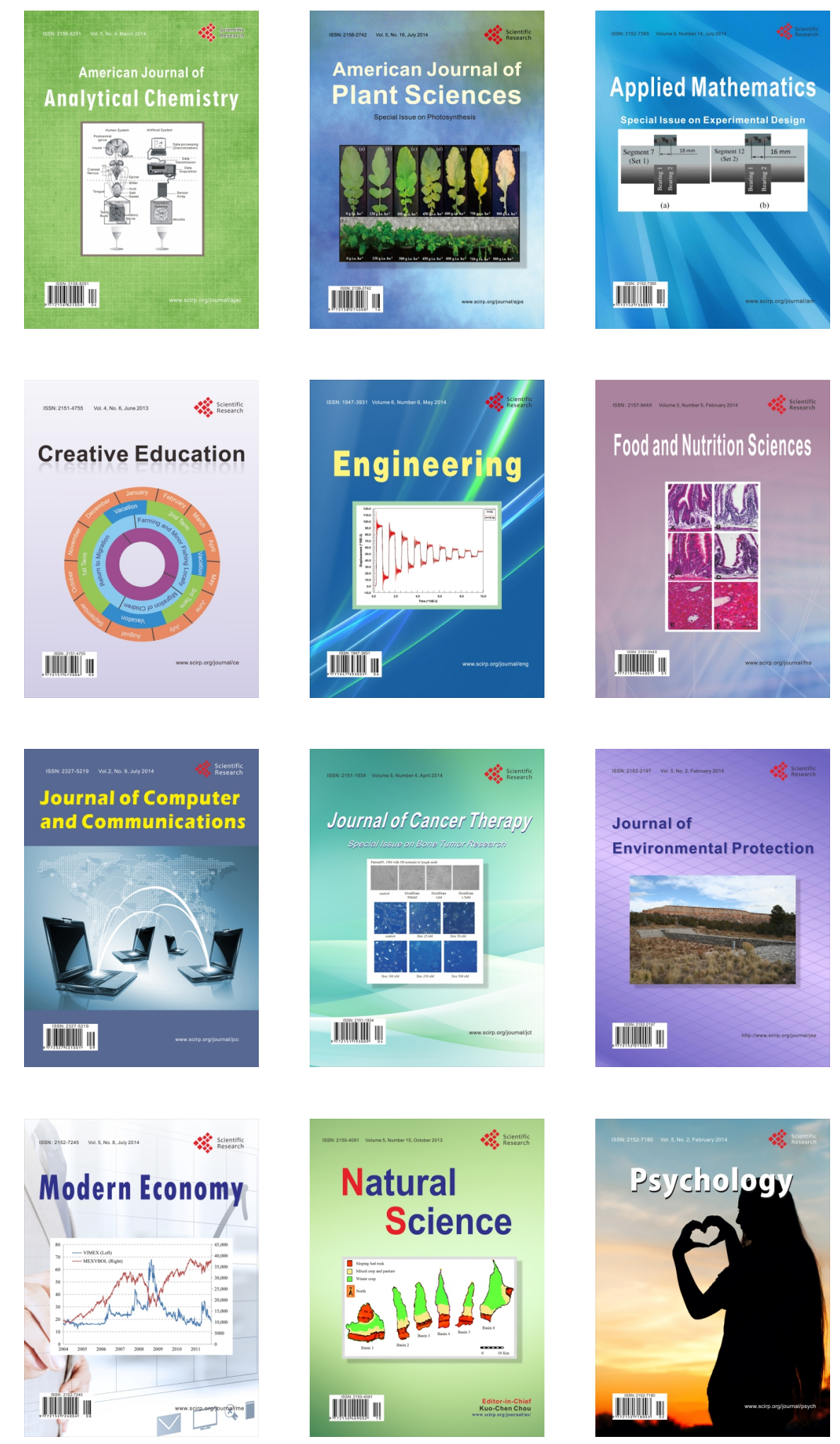